\title{
Numerical Study of Effect of Ridge-Weathering Thickness Effect on the Ground Motion Amplification
}

\author{
Vinay Kumar, J.P. Narayan and Manoj Kumar \\ Dept. of Earthquake Engineering, IIT Roorkee, India, \\ E-mail: vinaytomar23@gmail.com
}

\begin{abstract}
This paper presents the effects of ridge-weathering thickness on the ground motion amplification pattern. Seismic responses of the considered weathered ridge models have been computed using a $2 \mathrm{D}$ fourth-order-accurate staggered-grid finitedifference (FD) algorithm for the SH-wave and P-SV wave simulation in viscoelastic medium. The incorporation of realistic damping in the time-domain FD simulation is based on the GMB-EK rheological model. The analysis of the simulated responses of the weathered ridge models revealed considerable effects of weathering thickness on the ground motion characteristics. The obtained peak spectral amplification was of the order of 4.0 with respect to a response of a weathered horizontal layer overlying the rock. The computed average spectral amplification (ASA) for the SH-wave and PSV wave in the high and low frequency ranges revealed that in the high frequency range, the ASA is decreasing with an increase of weathering thickness. On the other hand in the low frequency range, the ASA is increasing with an increase of weathering thickness. Further, ASA is highly affected by the spectral peaks associated with the resonances in the weathered layer. Analysis of these results illustrates the importance of consideration of ride-weathering thickness effect on ground motion during seismic hazard assessment.
\end{abstract}

Keywords: Finite difference simulation, ridge-weathering effects, local site effects.

\section{INTRODUCTION}

The spatial variation in the ground motion characteristics caused by the undulating topography requires an explicit consideration in the design of the important facilities. The recorded ground motion and the observed damage patterns during past earthquakes and numerical simulations have revealed the topographic amplifications and de-amplifications (Trifunac and Hudson, 1971; Spudich et al., 1996; Celebi, 1987; Kawase and Aki, 1990; Celebi, 1991; Pedersen et al., 1994; Narayan and Rai, 2001). The quantification of the local site effects on the ground motion characteristics needs an efficient numerical method (Narayan, 2005, 2012; Narayan and Ram, 2006; Narayan and Kumar, 2008). In the past, seismic responses of homogeneous ridges of various shape and size have been simulated for the incident SH-, SV- and P-waves using different methods (Bouchon, 1973; Geli et al., 1988; Pitarka and Irikura, 1996; Narayan and Rao, 2003; Narayan, 2003; Chaljub et al., 2010). But, the numerically predicted topographic amplifications rarely exceeded 2.0 in the frequency band of interest (Geli et al., 1988). On the other hand, the topographic amplification exceeding 10 have been reported based on the earthquake records (Lee et al., 2009). The possible reasons behind such discrepancy may be the consideration of $2 \mathrm{D}$ 
models instead of 3D model, homogeneous ridges instead of heterogeneous one, use of ground motion record near the base of hill as a reference site for the computation of spectral amplifications and non-consideration of the surrounding topography in the simulations.

In order to find out whether weathering is responsible for the larger spectral amplification reported by Narayan and Kumar (2015), the effects of ridge weathering thickness on the ground motion characteristics is studied in details. In this paper the effects of ridge-weathering thickness on the ground motion of the $\mathrm{SH}$ - and P-SV waves are simulated. The SH-wave and P-SV wave time-domain viscoelastic finite-difference programs developed by Narayan and Kumar $(2013,2014)$ were used for the simulation of responses of various visco-elastic ridge models. The frequency-dependent damping in the time-domain FD simulations is incorporated based on the GMB-EK rheological model (Emmerich and Korn, 1987). A material independent anelastic function developed by Kristek and Moczo (2003) was used since it is preferable in case of material discontinuities in the FD grid. An improved vacuum formulation proposed by Zeng et al. (2012) is used as a free surface boundary condition. Both the sponge boundary (Israeli and Orszag, 1981) and A1 absorbing boundary (Clayton and Engquist, 1977) conditions were implemented on the model edges to avoid the edge reflections (Kumar and Narayan, 2008).

\section{WEATHERED RIDGE MODELS}

In order to study the effects of the weathering thickness on the ground motion, $\mathrm{SH}$ and SV-waves responses, weathered ridge models (WTM1-WTM4) with shape-ratio 1.0 were considered. The semi-elliptical ridge-model has a fixed base width $1000 \mathrm{~m}$ and height as $500 \mathrm{~m}$. The shape-ratio is the ratio of height of ridge with the half-width of the base of the ridge. Fig. 1 shows a cross-section of semi-elliptical weathered ridge-model. The weathering thickness was taken as $12 \mathrm{~m}, 20 \mathrm{~m}, 32 \mathrm{~m}$ and $48 \mathrm{~m}$ in the WTM1-WTM4 models, respectively. The $\mathrm{P}$ - and $\mathrm{S}$-waves velocities and quality factors at reference frequency 1.0 $\mathrm{Hz}$, density and unrelaxed moduli for the ridge-weathering and rock are given in Table- 1 . Seismic responses along the free surface were computed at 41 equidistant $(50 \mathrm{~m}$ apart horizontally) receiver points extending from $1.0 \mathrm{~km}$ left to $1.0 \mathrm{~km}$ right of the axis of the ridgemodels. Ricker wavelet with $4.0 \mathrm{~Hz}$ dominant frequency was used as a source excitation function. A plane SH- or P-SV-wave front were developed using various point sources along a horizontal line.

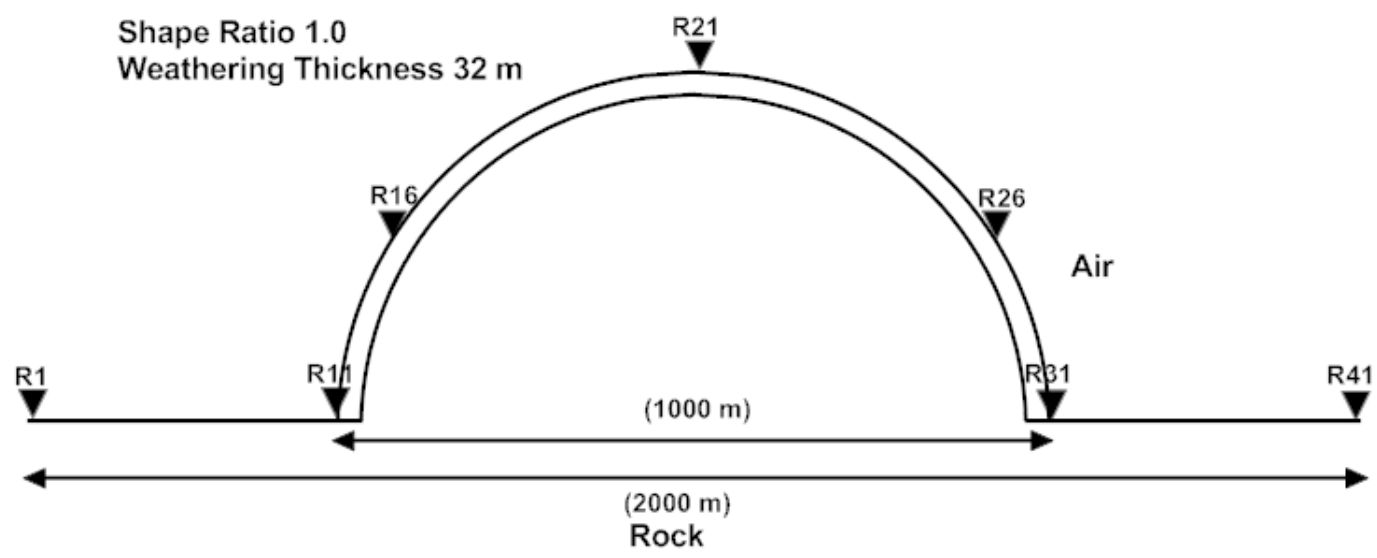

Fig. 1: Semi-elliptical ridge-model with a weathered layer. 
Table-1: P-and S-wave velocities and quality factors at a reference frequency, density and unrelaxed moduli for the ridge-weathering and the underlying rock-mass

\begin{tabular}{|c|c|c|c|c|c|c|c|c|}
\hline \multirow[t]{2}{*}{$\begin{array}{l}\text { Para- } \\
\text { meters }\end{array}$} & \multicolumn{2}{|c|}{$\begin{array}{l}\text { Velocity at } F_{R} \\
(\mathrm{~m} / \mathrm{sec})\end{array}$} & \multicolumn{2}{|c|}{$\begin{array}{l}\text { Quality Factor } \\
\text { at } F_{R}\end{array}$} & \multirow[t]{2}{*}{$\begin{array}{l}\text { Density } \\
\left(\mathrm{kg} / \mathrm{m}^{3}\right)\end{array}$} & \multicolumn{3}{|c|}{$\begin{array}{l}\text { Unrelaxed Moduli } \\
\text { (GPa) }\end{array}$} \\
\hline & S-wave & $\begin{array}{l}\text { P- } \\
\text { wave }\end{array}$ & $\begin{array}{l}\text { S- } \\
\text { wave }\end{array}$ & P-wave & & $M_{U}$ & $K_{U}$ & $\lambda_{U}$ \\
\hline Weathering & 300 & 561 & 30 & 56 & 1800 & 0.178 & 0.597 & 0.239 \\
\hline Rock & 1200 & 2078 & 120 & 208 & 2000 & 2.951 & 8.758 & 2.856 \\
\hline
\end{tabular}

WEATHERING THICKNESS EFFECTS ON SH-WAVE:

SH-wave responses of the WTM1-WTM4 ridge-models are shown in Fig.2 a-d for a vertically incident plane $\mathrm{SH}$-wave front. A decrease of amplitudes of both the incident and the reflected $\mathrm{SH}$-waves from the upper part of the ridge with an increase of weathering thickness can be inferred on the receiver points located above the ridge mass. An increase of duration of ground motion with an increase weathering thickness can also be inferred.
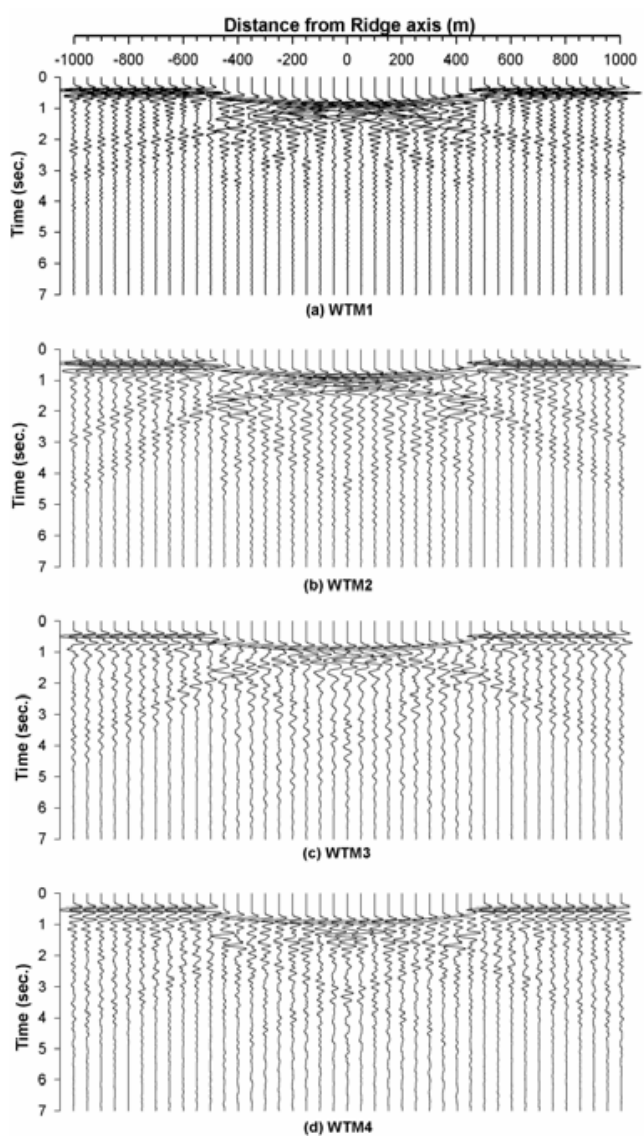

Fig. 2 a-d: The SH-wave responses of the WTM1-WTM4 models, respectively. 
The seismic responses of a model with a horizontal weathered layer overlying the rock were also computed for different weathering thickness. These responses have been used to compute the spectral amplification caused by the weathered ridge. Fig. 3 a-d depicts the spectral amplification of the $\mathrm{SH}$-wave at the ridge-top caused by weathered ridge with respect to a response a weathered horizontal layer. The analysis of Fig. 3 reveals that at certain frequency the spectral amplification has exceeded 3.0. Further, a decrease of largest spectral amplification value is decreasing with an increase of weathering thickness.

The average spectral amplifications (ASA) have been computed just using the average of ratio of spectra of responses corresponding to with and without the weathered ridge topography. A comparison of the ASA of the $\mathrm{SH}$-wave in the high and low frequency ranges for the WTM1-WTM4 models is shown in Fig.4 a \& b. Analysis of Fig. 4 depicts that in the high frequency range, the ASA is decreasing with an increase of weathering thickness. On the other hand, in the low frequency range, the ASA is increasing with an increase of weathering thickness. Further, it is highly affected by the spectral peaks associated with the resonances in the weathered layer, particularly in case of the WTM3 and WTM4 models where resonance frequencies in weathered layers are $2.24 \mathrm{~Hz}$ and $1.56 \mathrm{~Hz}$, respectively.

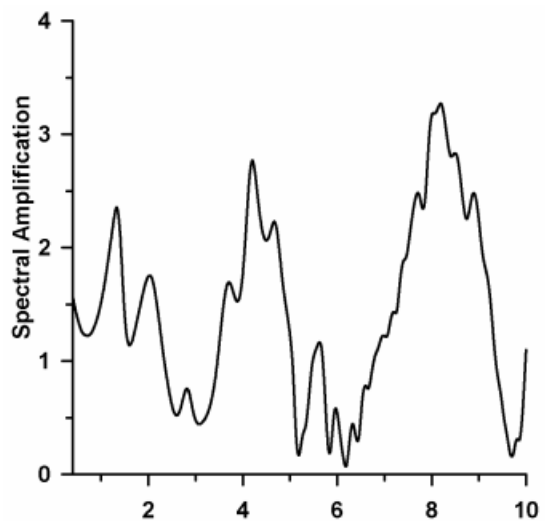

(a)

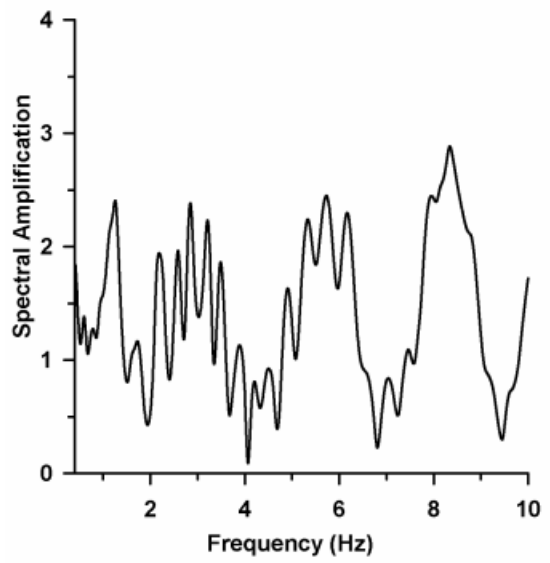

(c)

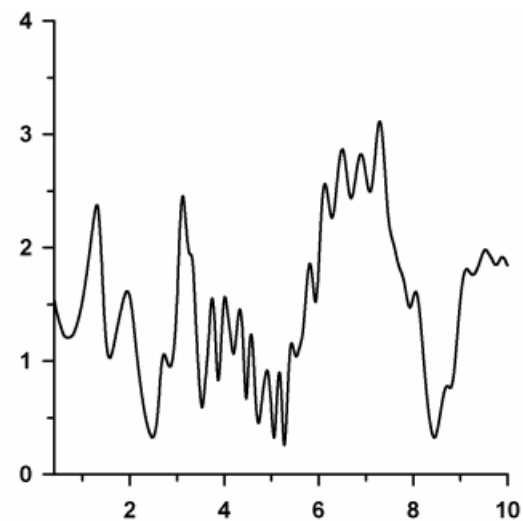

(b)

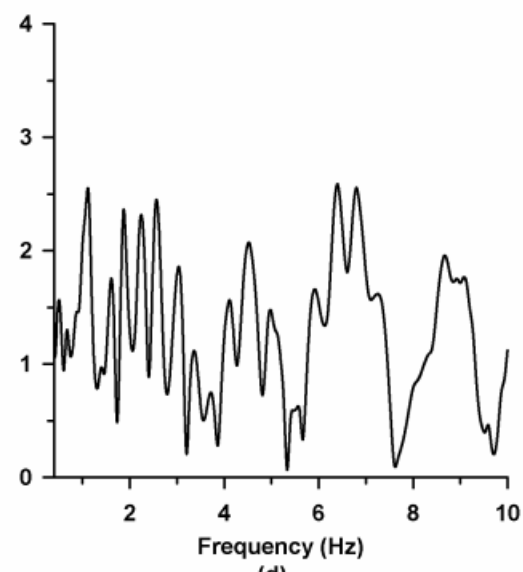

(d)

Fig. 3 a-d: A comparison of spectral amplification variation of the $\mathrm{SH}$-wave responses of WTM1-WTM4 models at top of the ridge model, respectively. 


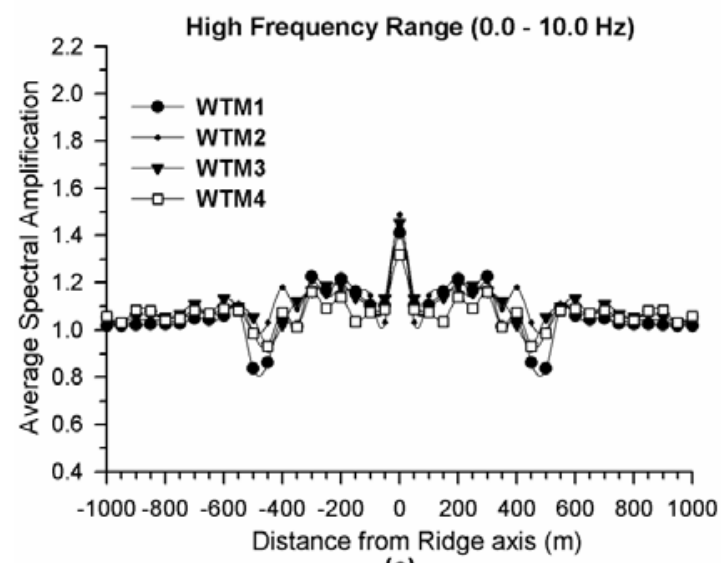

(a)

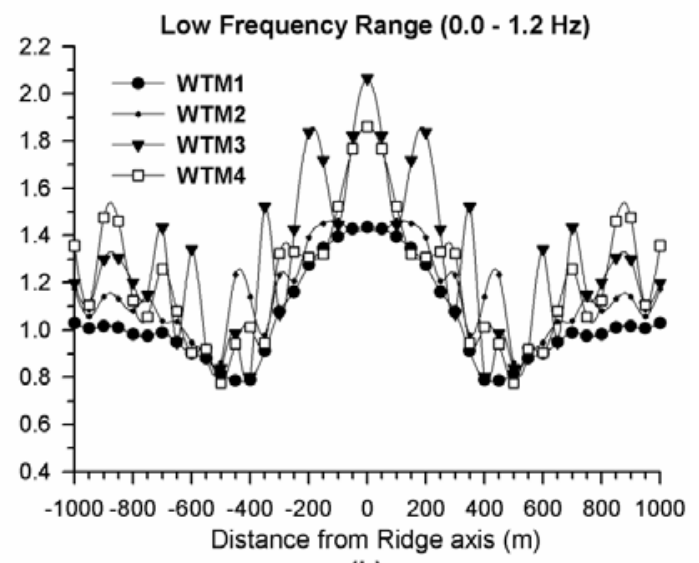

(b)

Fig. 4 a \& b: A comparison of ASA variation in the case of the SH-wave responses of the WTM1-WTM4 models in the high and low frequency ranges, respectively.

\section{WEATHERING THICKNESS EFFECTS ON P-SV WAVE}

The horizontal and vertical components of the SV-wave responses of the WTM1WTM4 weathered ridge-models are shown in Fig. 5 a-d and 6 a-d, respectively. The mode converted P-wave and the reflected P- and SV-waves are not clearly visible due to the increased duration of shaking in both the components. A decrease of amplitudes of the incident SV-wave, mode converted $\mathrm{P}$-wave and the reflected $\mathrm{P}$ - and SV-waves with an increase of weathering thickness can be inferred in both the components. An increase of duration of ground motion with an increase of weathering thickness can also be inferred, which was also observed in SH-wave.

The spectral amplification of the horizontal and vertical components of the SV-wave with respect to the horizontal component of response of a model containing a horizontal weathered layer are shown in Fig. 7 a-d and 8 a-d, respectively. The analysis of these Fig. reflects that the spectral amplification of the horizontal component of the SV-wave has gone up to 4.0. In case of the vertical components, the spectral amplification is negligible, this is obvious.

A comparison of the ASA of the horizontal and the vertical components of the SVwave in the high and low frequency ranges for the WTM1-WTM4 models are shown in Fig. 9 $a \& b ; 10$ a \& b, respectively. A decrease of ASA with an increase of weathering thickness in the high frequency range can be observed in the horizontal component and reverse was the case in the vertical component. On the other hand, an increase of ASA with an increase of weathering thickness in the low frequency range can be inferred in both the components. Further, it is highly affected by the spectral peaks associated with the resonance in the weathered layer. The spectral amplification peaks in case of the horizontal components of the SV-wave is lesser to that of the SH-wave. But, it is surprising to note that the ASA in the vertical components has gone up to 1.0. It means overall, the amplification of the SV-wave is more than that of the SH-wave. 
Numerical Study of Effect of Ridge-Weathering Thickness Effect on the Ground Motion Amplification: Kumar et al.

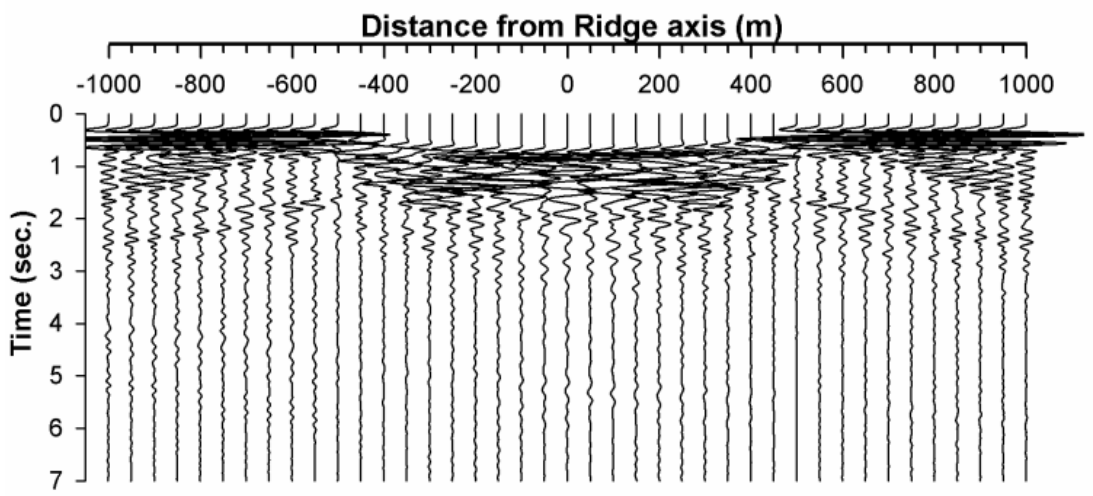

(a) WTM1

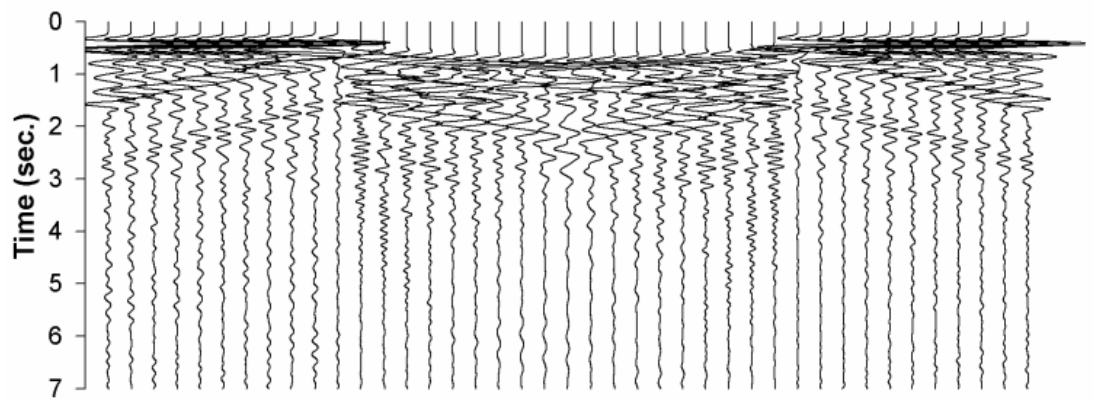

(b) WTM2

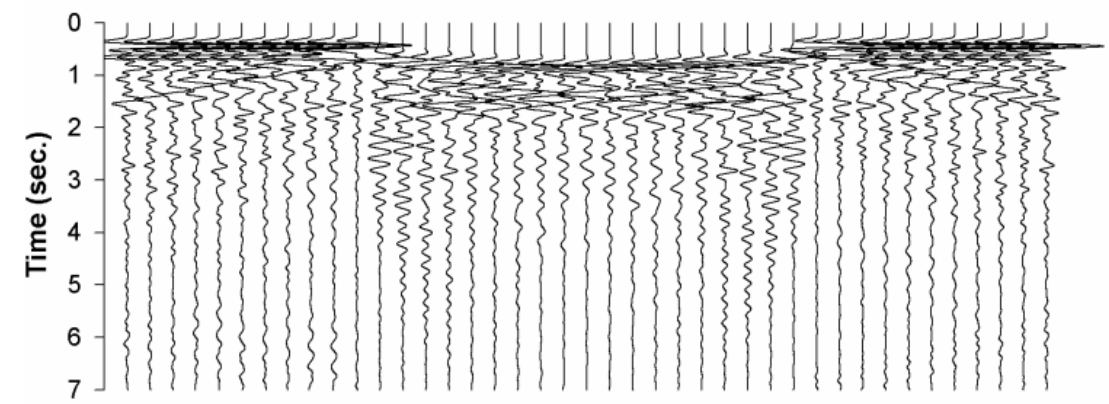

(c) WTM3

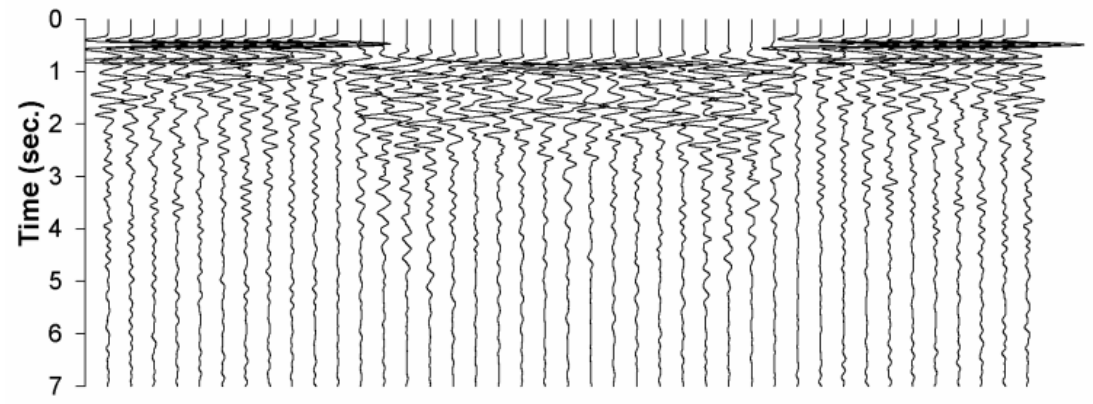

(d) WTM4

Fig. 5 a-d: The horizontal components of the SV-wave responses of the WTM1-WTM4 models, respectively. 


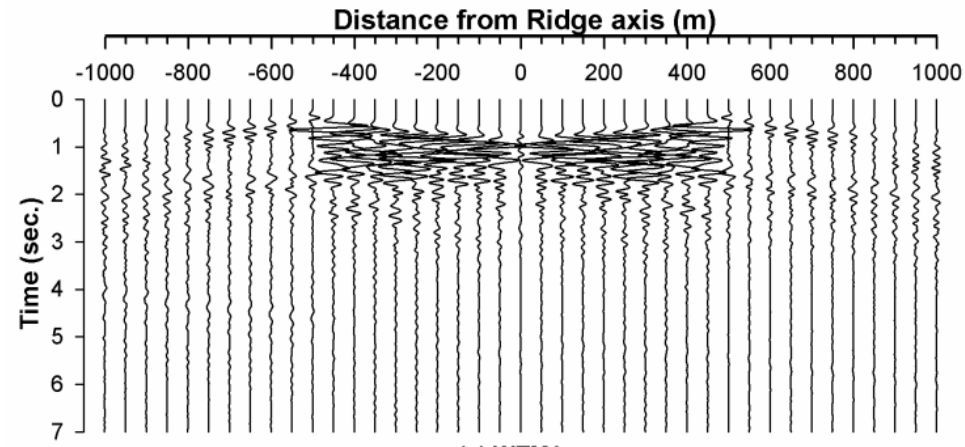

(a) WTM1
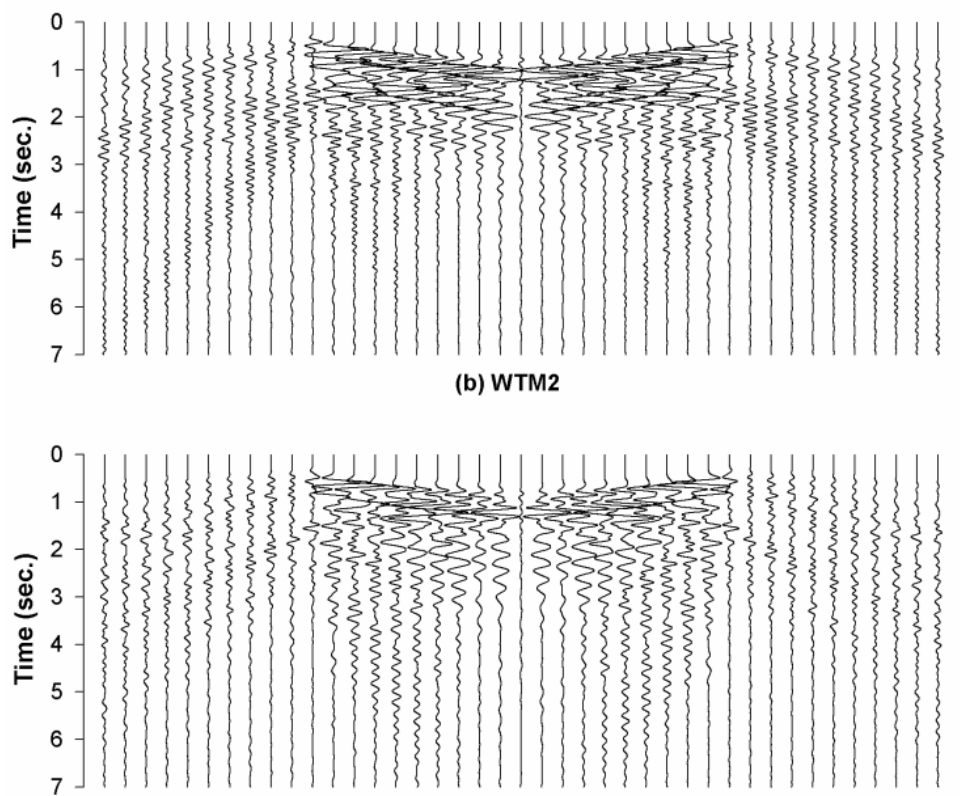

(c) WTM3

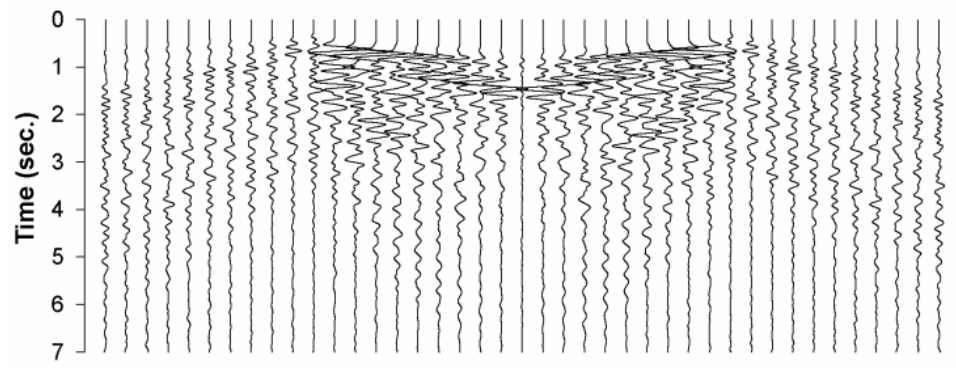

(d) WTM4

Fig.6 a-d: The vertical components of the SV-wave responses of the WTM1-WTM4 models, respectively. 


\section{CONCLUSIONS}

A decrease of amplitudes of both the SH-wave and P-SV with an increase of weathering thickness can be inferred on the receiver points located above the ridge mass.

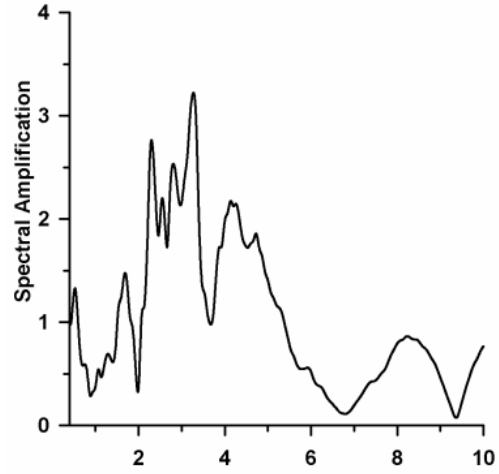

(a)

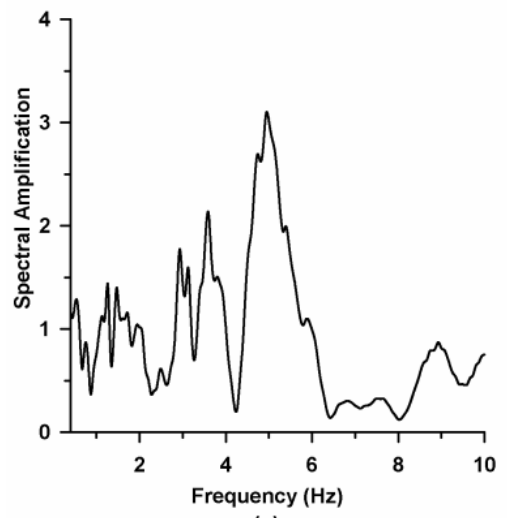

(c)

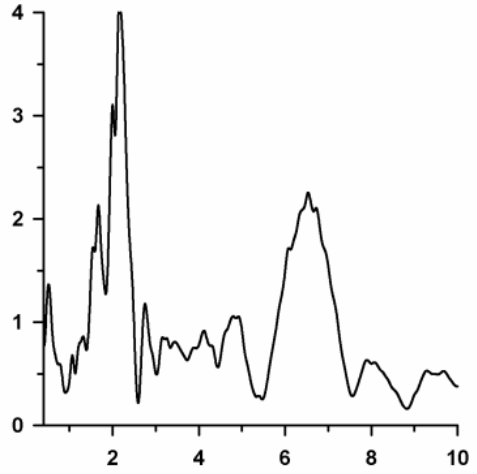

(b)

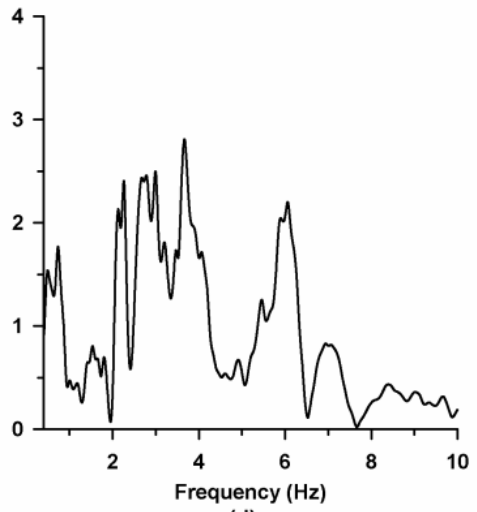

(d)

Fig. 7 a - d: A comparison of spectral amplification variation of the horizontal components of the SV-wave at the top of WTM1-WTM4 ridge models, respectively.

Further, it is highly affected by the spectral peaks associated with the resonances in the weathered layer, particularly in case of the WTM3 and WTM4 models where resonance frequencies in weathered layers are $2.24 \mathrm{~Hz}$ and $1.56 \mathrm{~Hz}$, respectively. A decrease of ASA of the SV-wave with an increase of weathering thickness in the high frequency range can be observed in the horizontal component and reverse was the case in the vertical component. On the other hand, an increase of the ASA with an increase of weathering thickness in the low frequency range can be inferred in both the components. A systematic effect of weathering thickness on the ASA was not inferred in both the $\mathrm{SH}$ - and SV-waves for the considered weathering-thickness range.

The obtained peak spectral amplifications in cases of both the SH- and SV-waves (exceeding 4.0) reflects that if a 3D modeling of a weathered layer is carried out along with the consideration of the surrounding topography then it may be expected that the observed large spectral amplifications can be verified based on the numerical simulations. Further, the large spectral amplifications may also be arising due to the consideration of the motion near 
Open access e-Journal

Earth Science India eISSN: $0974-8350$

Vol. 10 (IV), October, 2017, pp. 167 - 178

Earth Science India

http://www.earthscienceindia.info/

by the base of the ridge. The spectral de-amplification at a particular frequency may cause an unexpected (erroneous) amplification along the ridge flanks.
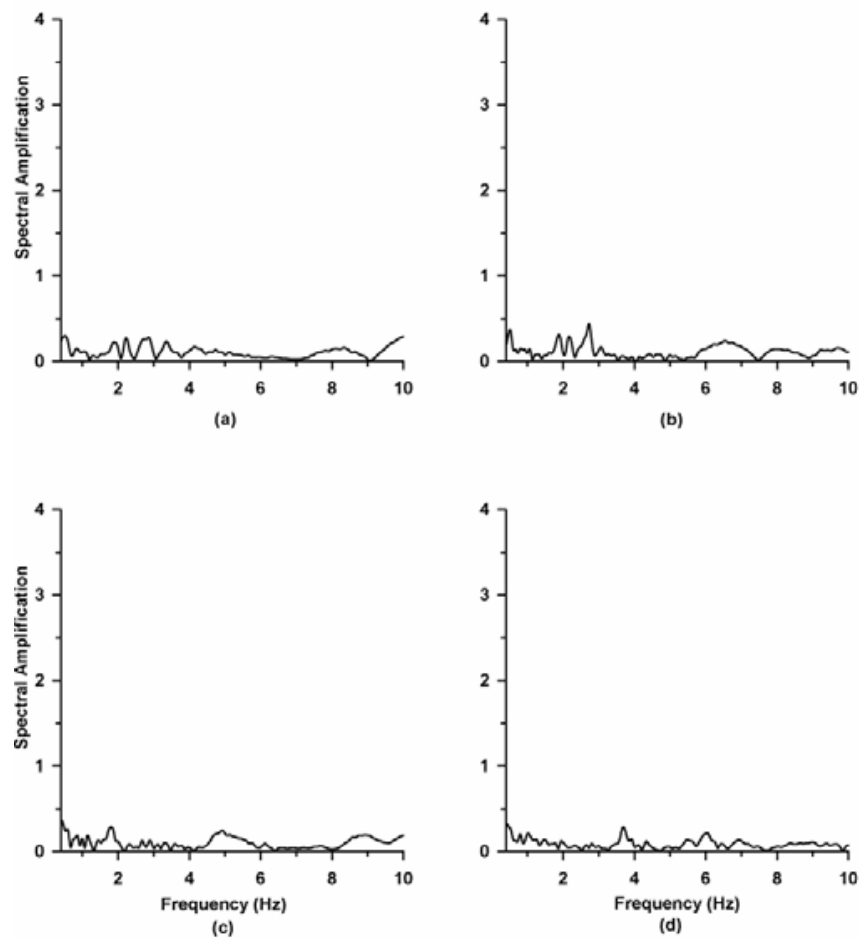

Fig. 8 a-d: A comparison of spectral amplification variation of the vertical components of the SV-wave at the top of WTM1-WTM4 ridge models, respectively.

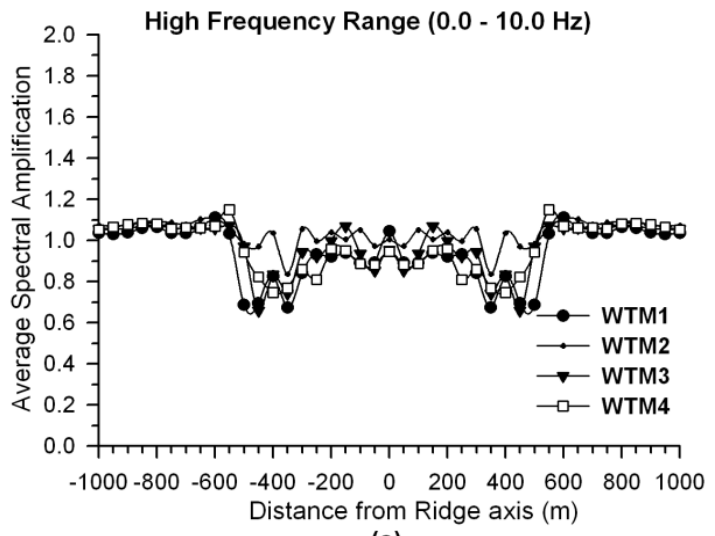

(a)

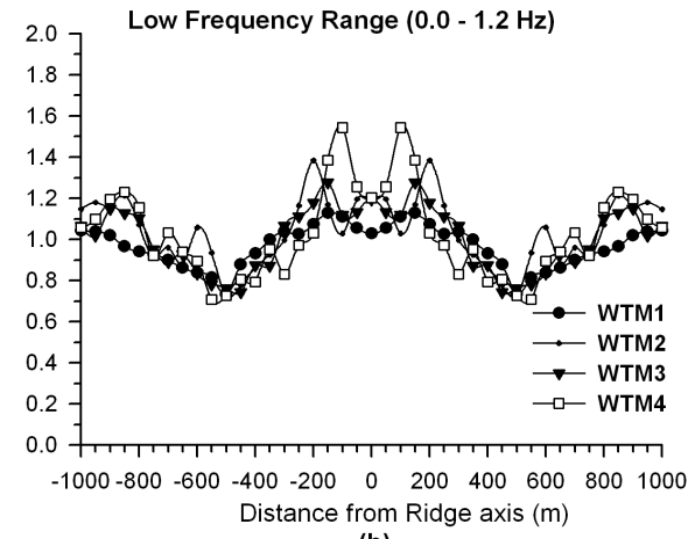

(b)

Fig. 9 a \& b: A comparison of ASA variation in the horizontal components of the SV-wave responses of WTM1-WTM4 models, respectively. 


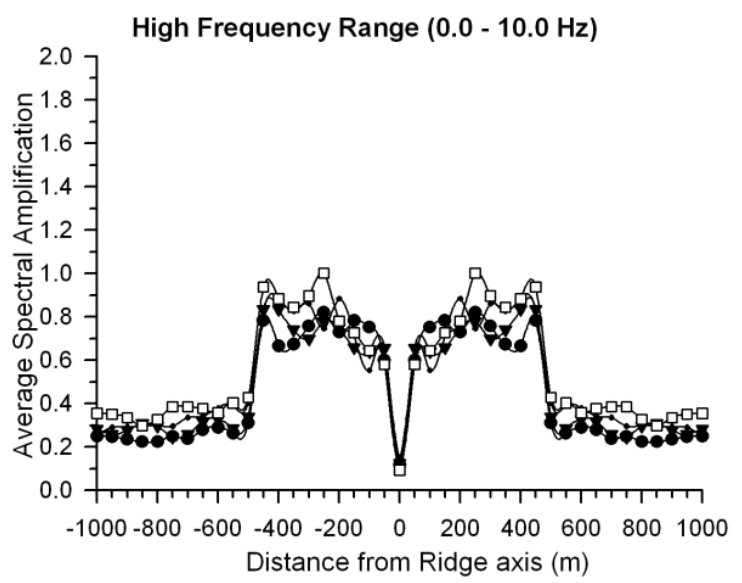

(a)

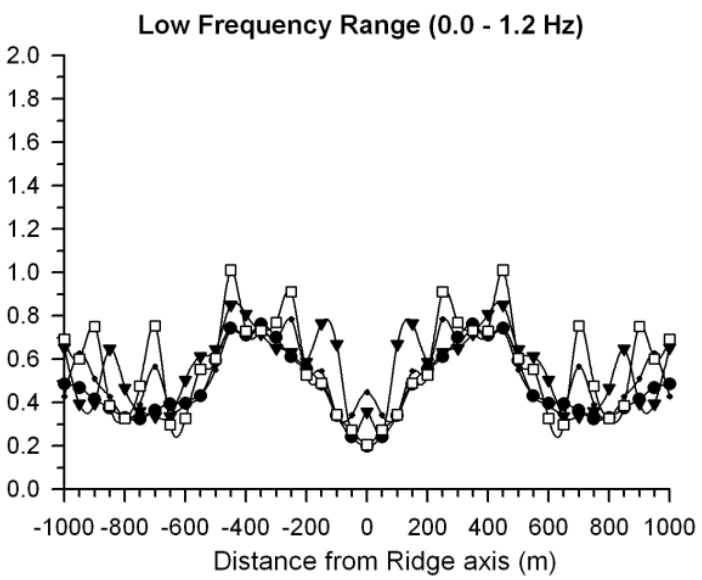

(b)

Fig. 10 a \& b: A comparison of ASA variation in the vertical components of the SV-wave responses of WTM1-WTM4 models, respectively.

\section{References}

Assimaki, D., Gazetas, G. and Kausel, E. (2005) Effects of local soil conditions on the topographic aggravation of seismic motion: Parametric investigation and recorded field evidence from the 1999 Athens earthquake. Bull. Seismo. Soc. Am., v. 95, pp. 1059-1089.

Bard, P.-Y. and Tucker, B. E. (1985) Underground and ridge site effects: A comparison of observation and theory. Bull. Seism. Soc. Am., v. 75, pp. 905-922.

Bard, P.-Y. and Meneroud, J.P. (1987) Modification du signal sismique par la topographie. Cas de la vallée de la Roya (Alpes-Maritimes). Bull. liaison Laboratoires des Ponts-et-Chaussées, Numéro special "Risques Naturels" 150-151, 140-151 (in French).

Bouchon, M. (1973) Effect of topography on surface motion. Bull. Seismo. Soc. Am., v. 63, pp. 615632.

Boore, D. M. (1972) Finite difference methods for seismic wave propagation in heterogeneous materials. In: B. A. Bolt (ed.) Methods in Computational Physics, v. 11, Seismology: Surface waves and Earth oscillations, Academic Press, pp. 1-37.

Celebi, M. (1987) Topographical and geological amplifications determined from strong motion and aftershock records of the 3 March 1985 Chile earthquake. Bull. Seism. Soc. Am., v. 77, pp. $1147-1167$.

Celebi, M. (1991) Topographic and geological amplification: case studies and engineering Implications. Structural Safety, v. 10, pp. 199-217.

Chaljub, E., Moczo, P., Tsuno, S., Bard, P.-Y., Kristek, J., Kaser, M., Stupazzini, M. and Kristekova, M. (2010) Quantitative comparison of four numerical predictions of 3D ground motion in the Grenoble valley, France. Bull. Seism. Soc. Am., v. 100, pp. 1427-1455.

Clayton, R.W. and Engquist, B. (1977) Absorbing boundary condition for acoustic and elastic wave equations. Bull. Seism. Soc. Am., v. 67, pp. 1520-1540.

Emmerich, H. and Korn, M. (1987) Incorporation of attenuation into time-domain computations of seismic wave field. Geophys., v. 52, pp. 1252-1264.

Faccioli, E. (1991) Seismic amplification in the presence of geological and topographic irregularities. Proceedings, $2^{\text {nd }}$ International Conference on Recent Advances in Geotechnical Earthquake Engineering and Soil Dynamics, St. Louis Missouri, v. 2, 1779-1797.

Gaffet, S. and Bouchon, M. (1989) Effects of two-dimensional topographies using the discrete wave number-boundary integral equation method in P-SV cases, J. Acoust. Soc. Am., 85, 22772283.

Geli, L., Bard, P.Y. and Beatrice, J. (1988) The effect of topography on earthquake ground motion: a review and new results. Bull. Seism. Soc. Am., v. 78, pp. 42-63. 
Open access e-Journal

Earth Science India eISSN: $0974-8350$

Vol. 10 (IV), October, 2017, pp. 167 - 178

Earth Science India

http://www.earthscienceindia.info/

Israeli, M. and Orszag, S.A. (1981) Approximation of radiation boundary condition. Jr. Comp. Physics v. 41 , pp. $115-135$

Kamalian M., Jafari M. K., Sohrabi-Bidar A., Razmkhah, A. and Gatmiri, B. (2006) Time- Domain TwoDimensional Site Response Analysis of Non-Homogeneous Topographic Structures by A Hybrid FE/BE Method; Soil Dynamics and Earthquake Engineering, 26,753-765.

Kawase, H. and Aki, K. (1990) Topography effect at the critical SV-wave incidence possible explanation of damage pattern by the Whittier narrows, California earthquake of 1 October 1987. Bull. Seism. Soc. Am., v. 80, pp. 1-22.

Kristeck, J., and P. Moczo (2003) Seismic wave propagation in viscoelastic media with material disconuties- a $3 \mathrm{D} 4^{\text {th }}$ order staggered grid finite difference modeling. Bull. Seism. Soc. Am, v. 93, pp. 2273-2280.

Kumar, S. and Narayan, J.P. (2008) Implementation of absorbing boundary conditions in a $4^{\text {th }}$ order accurate $\mathrm{SH}$-wave staggered grid finite difference program with variable grid size. Acta Geophys., v. 56, pp. 1090-1108.

Kumar. V. and Narayan, J.P. (2013) Study of combined effects of sediment rheology and anticlinal basement topography on ground motion characteristics. Geofizika., v. 30, v. 75-93.

Lee, S.J., Komatitsch, D., Huang, B.S. and Tromp, J. (2009) Effects of topography on seismic wave propagation: an example from northern Taiwan. Bull. Seism. Soc. Am., v. 99, pp. 314-325.

Levander, A.R. (1988) Fourth-order finite-difference P-SV seismograms. Geophys., v. 53, pp. 14251436.

Moczo, P., Kristek, J., Vavrycuk V., Archuleta, R.J. and Halada, L (2002). 3D heterogeneous staggered-grid finite-difference modelling of seismic motion with volume harmonic and arithmetic averaging of elastic moduli and densities. Bull. Seism. Soc. Am., v. 92, pp. 30423066.

Narayan, J.P. and Rai, D.C. (2001) An observational study of local site effects in Chamoli earthquake, Proceedings of 'Workshop on recent earthquakes of Chamoli and Bhuj', Indian Society of Earthquake Technology, Roorkee, May 24-26, pp. 273-280.

Narayan, J.P. and Rao, P.V. Prasad (2003) Two and half dimensional simulation of ridge effects on the ground motion characteristics. Pure Appl. Geophys., v. 160, pp. 1557-1571.

Narayan, J.P., (2003). Simulation of ridge weathering effects on the ground motion characteristics. Jr. Earthquake Engg., v. 7, pp. 447-461.

Narayan, J.P. (2005) Study of basin-edge effects on the ground motion characteristics using 2.5-D modeling. Pure Appl. Geophys., v. 162, pp.1-17.

Narayan, J.P. and Ram, A. (2006) Study of effects of underground ridge on the ground motion characteristics. Geophys. Jr. Int., v. 165, pp. 180-196.

Narayan, J.P. and Kumar, S. (2008) A fourth order accurate SH-wave staggered grid finite-difference algorithm variable grid size and VGR-stress imaging technique. Pure Appl. Geophys., v. 165, pp. 271-295.

Narayan, J.P. (2012) Effects of P-wave and S-wave impedance contrast on the characteristics of basin transduced Rayleigh waves. Pure Appl. Geophys., 169, 693-709.

Narayan, J.P. and Kumar, V. (2012) Numerical study of effects of synclinal basement topography on ground motion characteristics (Paper No. 3144). Proc. of $15^{\text {th }}$ World Conference on Earthquake Engineering (15WCEE). Lisbon, Portugal, September 24-28.

Narayan, J.P. and Kumar, V. (2013) P-SV wave time-domain finite-difference algorithm with realistic damping and a combined study of effects of sediment rheology and basement focusing. Acta Geophysica (in press).

Narayan, J.P. and Kumar, V. (2015) A numerical study of effects of ridge-weathering and ridgeshape-ratio on the ground motion characteristics, Journal of Seismology, v. 19, pp. 83-104.

Pedersen, H. A., LeBrun, B., Hatzfeld, D., Campillo, M. and Bard, P.Y. (1994) Ground motion amplitude across ridges. Bull. Seism. Soc. Am., v. 84, pp. 1786-1800.

Pitarka, A. and Irikura, K. (1996) Modeling 3-D surface topography by finite-difference method: the Kobe JMA station site case study. Geophys. Res. Lett., v. 23, pp. 2723- 2732.

Sanchez- Sesma, F.J. and Campillo M. (1991) Diffraction of P, SV, and Rayleigh wave by topographic features: a boundary integral formulation. Bull. Seism. Soc. Am., v. 81, pp. 2234-2253. 
Numerical Study of Effect of Ridge-Weathering Thickness Effect on the Ground Motion Amplification: Kumar et al.

Spudich, P., Hellweg, M., and Lee, W. H. K. (1996) Directional topographic site response at Tarzana observed in aftershocks of the 1994 Northridge, California, earthquake: implications for mainshock motions. Bull. Seism. Soc. Am., v. 86, pp. 193-208.

Trifunac, M. D. and Hudson, D.E. (1971) Analysis of the Pacoima Dam Accelerogram, San Fernando, California Earthquake of 1971. Bull. Seism. Soc. Am., v. 61, pp. 1393-1411.

(Received: 06.02.2017; Accepted: 17.10.2017) 